\title{
Shamba Maisha: Pilot agricultural intervention for food security and HIV health outcomes in Kenya: design, methods, baseline results and process evaluation of a cluster-randomized controlled trial
}

\author{
Craig R Cohen ${ }^{1,5^{*}}$, Rachel L Steinfeld ${ }^{1}$, Elly Weke ${ }^{6}$, Elizabeth A Bukusi ${ }^{6}$, Abigail M Hatcher ${ }^{1,10}$, Stephen Shiboski ${ }^{3}$,
} Richard Rheingans ${ }^{8}$, Kate M Scow ${ }^{9}$, Lisa M Butler ${ }^{11}$, Phelgona Otieno ${ }^{7}$, Shari L Dworkin ${ }^{4,5}$ and Sheri D Weiser ${ }^{2,5}$

\begin{abstract}
Background: Despite advances in treatment of people living with HIV, morbidity and mortality remains unacceptably high in sub-Saharan Africa, largely due to parallel epidemics of poverty and food insecurity.

Methods/Design: We conducted a pilot cluster randomized controlled trial (RCT) of a multisectoral agricultural and microfinance intervention (entitled Shamba Maisha) designed to improve food security, household wealth, HIV clinical outcomes and women's empowerment. The intervention was carried out at two HIV clinics in Kenya, one randomized to the intervention arm and one to the control arm. HIV-infected patients $>18$ years, on antiretroviral therapy, with moderate/severe food insecurity and/or body mass index (BMI) $<18.5$, and access to land and surface water were eligible for enrollment. The intervention included: 1$)$ a microfinance loan ( $\$ 150)$ to purchase the farming commodities, 2) a micro-irrigation pump, seeds, and fertilizer, and 3) trainings in sustainable agricultural practices and financial literacy. Enrollment of 140 participants took four months, and the screening-to-enrollment ratio was similar between arms. We followed participants for 12 months and conducted structured questionnaires. We also conducted a process evaluation with participants and stakeholders 3-5 months after study start and at study end.
\end{abstract}

Discussion: Baseline results revealed that participants at the two sites were similar in age, gender and marital status. A greater proportion of participants at the intervention site had a low BMI in comparison to participants at the control site ( $18 \%$ vs. $7 \%, p=0.054)$. While median CD4 count was similar between arms, a greater proportion of participants enrolled at the intervention arm had a detectable HIV viral load compared with control participants ( $49 \%$ vs. $28 \%$, respectively, $\mathrm{p}<0.010$ ). Process evaluation findings suggested that Shamba Maisha had high acceptability in recruitment, delivered strong agricultural and financial training, and led to labor saving due to use of the water pump. Implementation challenges included participant concerns about repaying loans, agricultural challenges due to weather patterns, and a challenging partnership with the microfinance institution. We expect the results from this pilot study to provide useful data on the impacts of livelihood interventions and will help in the design of a definitive cluster RCT.

Trial registration: This trial is registered at ClinicalTrials.gov, NCT01548599.

Keywords: HIV; Food insecurity; Microfinance; Agriculture; Livelihoods; Intervention

\footnotetext{
*Correspondence: craig.cohen@ucsf.edu

'Department of Obstetrics, Gynecology \& Reproductive Sciences, University

of California San Francisco, 550 16th Street, San Francisco, CA 94158, USA

${ }^{5}$ Center of Expertise in Women's Health \& Empowerment, University of

California Global Health Institute, San Francisco, CA, USA

Full list of author information is available at the end of the article
} 


\section{Background}

Despite major advances in care and treatment of those living with HIV, morbidity and mortality among people living with HIV/AIDS (PLHIV) remains unacceptably high in sub-Saharan Africa, largely due to parallel epidemics of poverty and food insecurity (Weiser et al. 2011). There are an estimated 35.3 million PLHIV worldwide, $70.8 \%$ of whom live in sub-Saharan Africa (Global report 2013). Food insecurity, defined as "the limited or uncertain availability of nutritionally adequate, safe foods or the inability to acquire personally acceptable foods in socially acceptable ways," (Normen et al. 2005) is also highly prevalent in sub-Saharan Africa, where 240 million persons, or one in every four people, are estimated to be food insecure (FAO 2010). The prevalence of food insecurity is even higher among PLHIV in sub-Saharan Africa. Studies from Kenya and Uganda have shown that over 50\% of PLHIV are moderately or severely food insecure (Mbugua et al. 2008; Weiser et al. 2010a).

Food insecurity and HIV/AIDS are leading causes of morbidity and mortality in sub-Saharan Africa and are inextricably linked, with each condition heightening vulnerability to, and worsening the severity of the other condition (Weiser et al. 2011). Food insecurity enhances HIV acquisition risk through increased risky sex and also increases susceptibility to HIV among those who are exposed (Weiser et al. 2007; Campbell et al. 2009; Webb-Girard et al. 2012; Weiser et al. 2011). Among PLHIV, food insecurity inhibits antiretroviral therapy (ART) initiation, retention in care, and ART adherence (Weiser et al. 2010b; Goudge \& Ngoma 2011; Nagata et al. 2012; Weiser et al. 2009a; Wang et al. 2011; McMahon et al. 2011; Weiser et al. 2009b; Weiser et al. 2012). Food insecurity has been associated with a range of adverse clinical effects among PLHIV, including declines in physical health status (Weiser et al. 2009c; Weiser et al. 2012), decreased viral suppression (Weiser et al. 2009a; Kalichman et al. 2010a), worse immunologic status (Weiser et al. 2009c; Kalichman et al. 2010b), increased incidence of serious illness (Tsai et al. 2011), and increased mortality (Weiser et al. 2009b). In turn, HIV/AIDS worsens food insecurity by eroding economic productivity (Larson et al. 2008; McIntyre et al. 2006; Russell 2004), reducing social support due to HIV stigma (Tsai et al. 2011), and increasing medical expenses (McIntyre et al. 2006).

Although there has been a substantial increase in the allocation of international resources towards HIV care and treatment programs in Africa, food insecurity can significantly compromise the effectiveness of these programs due to its effects on morbidity and mortality as described above (Mamlin et al. 2009). As a result, the World Health Organization, UNAIDS and the World
Food Programme have recommended integrating sustainable food production strategies into HIV/AIDS programming (Food and Nutrition Technical Assistance. HIV/AIDS: A Guide For Nutritional Care and Support; Nutrition and HIV/AIDS 2001; Blumberg \& Dickey 2003; World Food Program 2003). Specifically, UNAIDS calls for international partners to "fund multisectoral HIV programming that incorporates effective food and nutrition interventions, in line with scale-up towards universal access to prevention, treatment, care and support" (UNAIDS Policy Brief 2008). Yet, little research exists to document the beneficial effect of food security or sustainable agricultural interventions on antiretroviral (ARV) adherence, HIV clinical outcomes, women's empowerment and HIV transmission risk behaviors among PLHIV in Africa or elsewhere.

To date, no randomized controlled trials have been conducted in resource-limited settings to examine the impacts of either food supplementation or sustainable food production strategies on HIV morbidity and mortality (Mahlungulu et al. 2007). Several small studies in developing countries have demonstrated the potential for programs that address food security to affect health outcomes among PLHIV (Mamlin et al. 2009; Cantrell et al. 2008; Agricultural initiatives for health in Haiti; Ochai 2008; Njenga et al. 2009; Byron et al. 2008). Yet, existing intervention approaches to impacting food security have focused primarily on direct macronutrient supplementation, which may be somewhat limited in its scalability and sustainability (Sztam et al. 2010). Livelihood interventions, which address upstream causes of food insecurity, may have a better chance of improving health outcomes, and may be more sustainable. Similarly, while microcredit programs can improve health and prevent disease acquisition by targeting poverty and gender inequality (Ashburn et al. 2008; Kim et al. 2008; Schuler \& Hashemi 1994), they have been criticized in terms of their effectiveness as a stand-alone strategy. As a result, experts have recommended integrating microfinance and other livelihood approaches to maximize HIV prevention and treatment efforts and reduce poverty (Dworkin \& Blankenship 2009; Weinhardt et al. 2009). Income generating activities are well suited to improving food security (Diagne 1998; Doocy et al. 2005), and to retaining patients in HIV care (Mamlin et al. 2009; Gomez et al. 2004).

Following our previously published theoretical model (Weiser et al. 2011), we set out to test the impact of a multisectoral agricultural intervention on HIV health outcomes and transmission risk behaviors in rural Kenya. In a previous small feasibility study conducted by our group, we showed that using a human powered irrigation hip pump combined with a microfinance loan led to increases in crop yields, household income, CD4 
counts and BMI (Pandit et al. 2010). In the current study, we developed and tested a modified version of this combination agricultural and microfinance intervention called Shamba Maisha, Kiswhahili for "farm life," in a small community randomized control trial. In this study, we aimed to explore the acceptability and feasibility of the intervention and control conditions that will be used in a subsequent, larger cluster randomized controlled trial, and examined preliminary impacts on outcomes of interest. Two similar district hospitals in southern Nyanza Province were randomized: one to the intervention and the other to the control group. We hypothesized that this multisectoral intervention will improve food insecurity, household wealth and HIV health outcomes. We developed and tested a theoretical framework for the pathways through which this multisectoral agricultural intervention may improve health. In this paper, we described our conceptual framework, study methods, baseline findings, as well as process evaluation findings of successes and challenges with implementation.

\section{Methods \\ Setting}

The study took place in Rongo and Migori districts in Nyanza Province, Kenya. As of 2008, the HIV prevalence in Nyanza Province, Kenya, was estimated to be $15.3 \%$, more than twice the national average (Kenya National Bureau of Statistics and ICF Macro 2010). Nearly all HIV-affected households in a recent Kenyan survey were considered to be moderately or severely food insecure (Mbugua et al. 2008). The province also has a significant shortage of accessible water making communities vulnerable to the impacts of drought, and a heavy dependence on an unstable agricultural sector. Farming and fishing are the primary means of income generation in Nyanza Province. Lack of irrigation and unpredictable rainfall leading to an inconsistent water supply remains a central barrier to successful farming for many in the region (Government of Kenya 2008).

\section{Description of intervention}

The Shamba Maisha intervention consisted of three components: 1$)$ a microfinance loan $(\sim 150)$ to purchase the farming commodities, 2) a micro-irrigation pump, seeds, fertilizer and pesticides, and 3) trainings in sustainable agricultural practices and financial literacy. KickStart, an international non-governmental organization (NGO), along with technical support of agricultural experts from the University of California Davis, led the agricultural component of the intervention. Adok Timo, a microfinance institution in Nyanza Province, implemented the economic aspects of the intervention with support from the UCSF and KEMRI research team. The intervention components are described below.

\section{Loan program}

The microfinance loans were managed by Adok Timo, which has branches in Nyanza Province. The intervention group received training on financial management and marketing skills prior to receiving the loan. All trainings took place on participant's farms or a nearby location. Participants were required to save 500 Kenyan shillings ( $\$ 6.00$ USD) prior to receiving the loan. Each participant received vouchers to purchase the following items: the Hip Pump, 50 feet of hosing, fertilizer, and government certified seeds. These materials were purchased at a local farm store ("agrovet"). Loan repayment could begin at any time, but farmers were expected to make a minimum payment after the first harvest, usually 4-6 months after planting. Farmers were expected to repay in full by the end of two harvest seasons (approximately one year); however, if regular payments have been made, this deadline was extended based on the guidelines set out by the microfinance institution. Participants were not asked to forfeit personal belongings to cover loan payments. Control participants were eligible for the microcredit loan and the Kickstart Hip Pump at the end of the 1-year follow-up period.

KickStart water pump and agricultural training: Irrigation technologies have been shown to improve agricultural output. (About KickStart) Recognizing the need for improved agricultural tools for poor farmers in Kenya, Kickstart developed a low-cost irrigation pump. These pumps enable farmers to irrigate their crops year-round avoiding dependence on seasonal rainfall thus capitalizing on higher crop prices in the marketplace. In prior evaluations in Kisumu Kenya, farmers using this hip pump have been able to enjoy up to a ten-fold increase in income (Brandsma 2003; Kihia \& Kamau 1999; Stevens 2002; World Bank 2010).

Prior to receiving the microfinance loan, participants in the intervention group received eight training modules. The training modules were delivered to groups of farmers on participant's farms or at a nearby location by agricultural trainers from Kickstart, the loan officer from Adok Timo, and the study coordinator. The agricultural portion of the training included a didactic session and practical demonstrations on sustainable farming techniques, seed selection, soil and water conservation, fertilization and crop rotation, integrated pest and disease management (IPM), pre \& post-harvest handling and marketing, the use of the MoneyMaker Hip Pump, and identifying improved market access for selling horticultural products. The field-based practical trainings were based on a training needs assessment and the crops selected by the participants. These trainings focused on plant spacing, seed selection, seed rate, crop combination, and a cost-benefit analysis for each crop selected and IPM. Participants were particularly interested in 
locally available materials for IPM like wood ash, Mexican marigold and livestock urine in controlling pests on crops to enable them to reduce cost and maximize profits. Participants also conducted a market survey as part of the pre \& post-harvest handling and marketing which revealed a large demand in the local markets for green vegetables and watermelon. The intervention participants also had an in-depth training on financial record keeping, the importance on savings and loans, and the basics of group dynamics.

\section{Intervention model}

The primary aim of the pilot study was to test if a multisectoral agricultural intervention improves food security and HIV health outcomes. We hypothesized that the proposed multisectoral agricultural intervention will improve food security, prevent treatment failure, reduce co-morbidities, and decrease secondary HIV transmission risk among PLHIV.

We developed an evidenced-based causal framework (Figure 1) to understand the pathways by which food insecurity negatively impacts health outcomes. Food insecurity negatively impacts health outcomes through nutritional, behavioral, and mental health pathways, which emerge directly from the definition of food insecurity (Weiser et al. 2011). In terms of nutritional pathways, food insecurity has been associated with macronutrient and micronutrient malnutrition (Rose \& Oliveira 1997; Lee \& Frongillo 2001), and weight loss, low body mass index (BMI), and low albumin have been shown to hasten progression to AIDS and death (Stringer et al. 2006; Zachariah et al. 2006; Johannessen et al. 2008). HIV also increases metabolic requirements (Babameto \& Kotler 1997; Macallan et al. 1995) and is associated with diarrhea and malabsorption of fat and carbohydrates
(Babameto \& Kotler 1997; Kotler et al. 1990; Stack et al. 1996; Fields-Gardner \& Fergusson 2004). Lack of food may also impede optimal absorption of certain ARVs (Gustavson et al. 2000; Bardsley-Elliot \& Plosker 2000; Food and Agriculture Organization 2010), which may contribute to treatment failure. In terms of behavioral pathways: Food insecurity is an important cause of ART non-adherence and treatment interruptions, (Weiser et al. 2010b; Weiser et al. 2009a; Kalichman et al. 2010a; Weiser et al. 2009d); Tuller et al. 2010) which are both wellknown determinants of HIV treatment outcomes (Parienti et al. 2004; Parienti et al. 2008; Oyugi et al. 2007). In addition to ART non-adherence and treatment interruptions, as a result of competing demands between food and other resources, food insecure individuals often miss scheduled clinic visits, and may be less likely to initiate ART (Weiser et al. 2010b; Tuller et al. 2010; Weiser et al. 2012). In terms of mental health pathways, food insecurity has been associated with depression and poor mental health status in sub-Saharan Africa and elsewhere, (Weiser et al. 2009c; Tsai et al. 2011; Anema et al. 2011) which in turn have been shown to independently contribute to lower ART adherence and worse HIV clinical outcomes (Ickovics et al. 2001; Tucker et al. 2003; Evans et al. 2002; Weiser et al. 2004). Food insecurity and poverty also contribute to lower levels of empowerment, including women's empowerment, which can negatively impact health outcomes for HIV. For example, in Uganda, among HIV-infected women low sexual relationship power is associated with malnutrition (Siedner et al. 2012), depression (Hatcher et al. 2012), and worse virologic outcomes (Weiser et al. 2010a, b).

Drawing upon this framework, we developed the intervention framework to describe the pathway by which we believe the multisectoral agrigultural intervention impacts

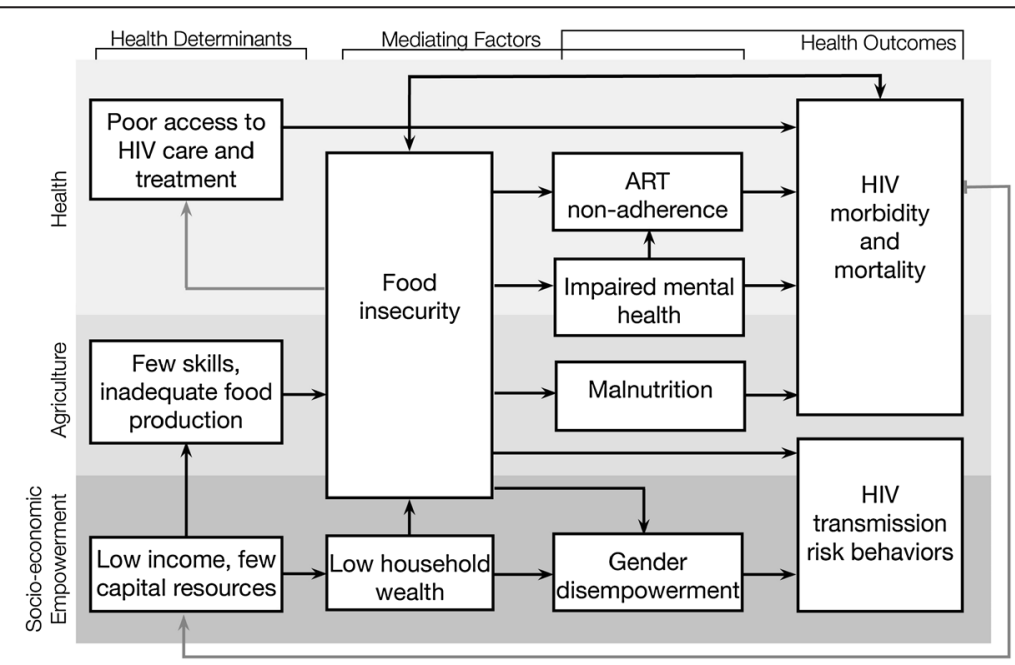

Figure 1 Shamba Maisha causal framework 
on mediating factors and eventually improves health outcomes among HIV-infected adults (Figure 2). Specifically, we hypothesized that: 1) The three intervention components together would directly lead to improvements in food security and household wealth (most proximal mediators); 2) Changes in food security and household wealth would, in turn, contribute to less macronutrient and micronutrient malnutrition (nutritional pathway), less anxiety, stress and depression (mental health pathway), improved ART adherence and retention in care (behavioral pathway) and improved gender empowerment; and 3) Through these pathways, the intervention would ultimately contribute to decreased HIV morbidity and mortality and fewer HIV transmission risk behaviors.

\section{Randomization}

We used a two-step process to select two sites from among 68 government health facilities in Rongo, Migori and Nyatike districts supported by Family AIDS Care \& Education Services (FACES), a collaboration between the University of California, San Francisco (UCSF), and the Kenyan Medical Research Institute (KEMRI) (Lewis Kulzer et al. 2012). First, we limited to 20 sites where there were an adequate number of PLHIV on ART at the time of the study, and where farming was a primary means of livelihood in the communities. Next, we selected two government health facilities for the pilot randomized controlled trial (RCT) according to the following criteria: a) having adequate numbers of PLHIV on ART with non-overlapping catchment areas; b) having catchment areas that were relatively similar to one another according to rainfall patterns, health, topography and socioeconomic status; and c) meeting practical requirements for the intervention, including acceptable characteristics in topography to enable use of the water pump, having water access year round, and having favorable soil composition to potentiate the intervention. One site was randomly selected as the intervention site and the other the control site by the study's biostatistician who used a computer random number generator and was not involved in fieldwork. Clinics, healthcare providers, patients, and researchers involved in implementing the study were not blinded to the allocation.

\section{Ethics statement}

The study was approved by the Committee on Human Research at UCSF and the Ethical Review Committee at KEMRI. All participants in the study gave written informed consent prior to enrollment in the study, and had the cost of their transportation reimbursed up to $800 \mathrm{Ksh}$ per clinic-based interviews ( \$9.4 USD) and $400 \mathrm{Ksh}$ for home-based interviews $(\$ 4.70)$. This clinical trial was registered at ClinicalTrials.gov (NCT01548599).

\section{Participants and recruitment}

The study population includes HIV-infected patients between the ages of 18-49 years receiving ART, have access to farm land and surface water, and have demonstrated evidence of moderate to severe food insecurity or malnutrition during the year preceding the study. Participants were recruited from Rongo (intervention site) and Migori (control site) District Hospitals in Nyanza Province beginning in April 2012. Research assistants introduced the study to patients waiting to be seen at the HIV clinic at the two health facilities. Individuals who expressed interest were consented and screened for eligibility. Among interested and potentially eligible individuals, home visits were conducted to verify that the participant had access to farming land and surface water. In addition to the eligibility criteria

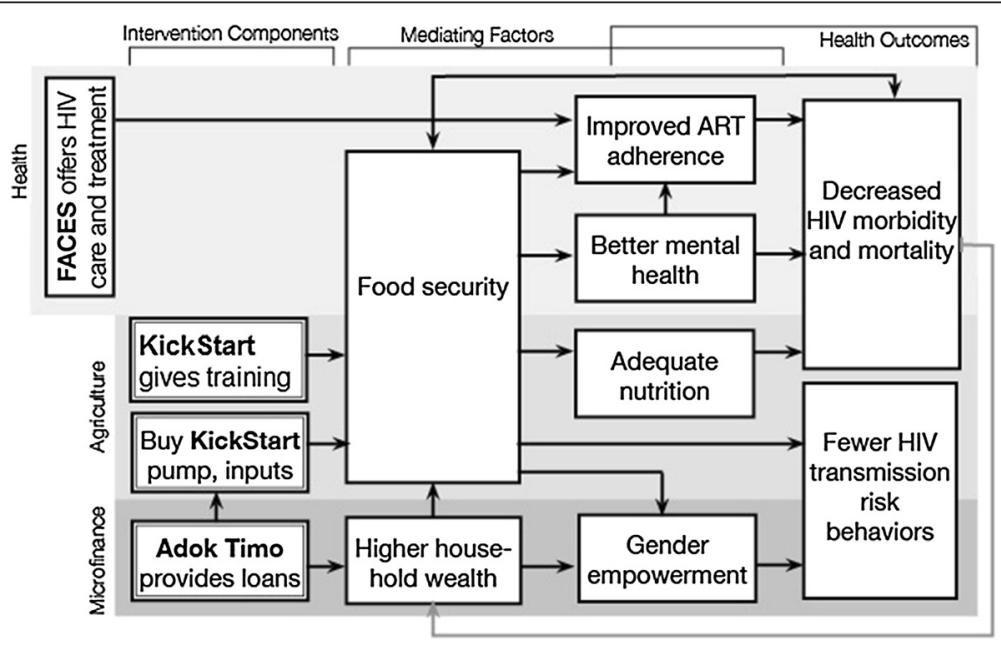

Figure 2 Shamba Maisha intervention framework 
above, the study also aimed to ensure that at least $40 \%$ of participants at each site were of each gender. Individuals who met eligibility criteria were enrolled in the study after providing written informed consent. At intervention sites, participants were enrolled in a savings program in anticipation of receiving the asset loan. Control participants also agreed to save the down payment $(\sim \$ 6)$ required for the loan by the study end. A total of 140 HIV-positive individuals were enrolled in the study during the period of April - July 2011 (See Figure 3); an additional two (1.4\%) eligible screened participants declined to participate in the study.

\section{Data collection}

Participants were followed quarterly for structured interviews and $\mathrm{ART}$ adherence assessments by unannounced pill counts at their home. Anthropometry (i.e., mid upper arm circumference measurements [MUAC] and BMI measurements) and phlebotomy for viral load and CD4 determinations were conducted every six months. Viral load testing was performed on venous blood at the Centers for Disease Control-Kenya laboratory on the COBAS TaqMan HIV viral load platform (Roche Molecular Diagnostics, Pleasanton, CA) with a lower limit of detection of $<20$ copies $/ \mathrm{mL}$. Absolute CD4 count testing was performed on whole blood using the
BD FACSCount (BD Bioscience, San Jose, CA). In addition, clinical data were abstracted from participant's medical records.

Structured interviews for clinical and sensitive behavioral data were administered at baseline, 6 months and 12 months at the clinic and included the following data (see Table 1): health care access and competing demands, ARV history and adherence, physical and mental health, social support, women's empowerment, stigma, HIV disclosure, alcohol use, and sexual behavior. Additionally, quarterly home visits were conducted to collect unannounced pill counts for ART adherence, food frequency, food security, income, housing, assets and wealth, and specific data related to agricultural output, labor, harvesting, marketing, and irrigation.

\section{Data collection methods}

Structured interviews administered at the health facility and at participants' farms or homes were conducted by trained research assistants who used a handheld computer tablet for data entry (Morotola ${ }^{\mathrm{m}}$ Xoom Android Tablets operating Open Data Kit (ODK) Collect (Hiarlaithe et al. 2014). Research assistants conducted structured interviews in the local language (Dholuo) or English and completed paper-based data collection forms for the majority of baseline data collection
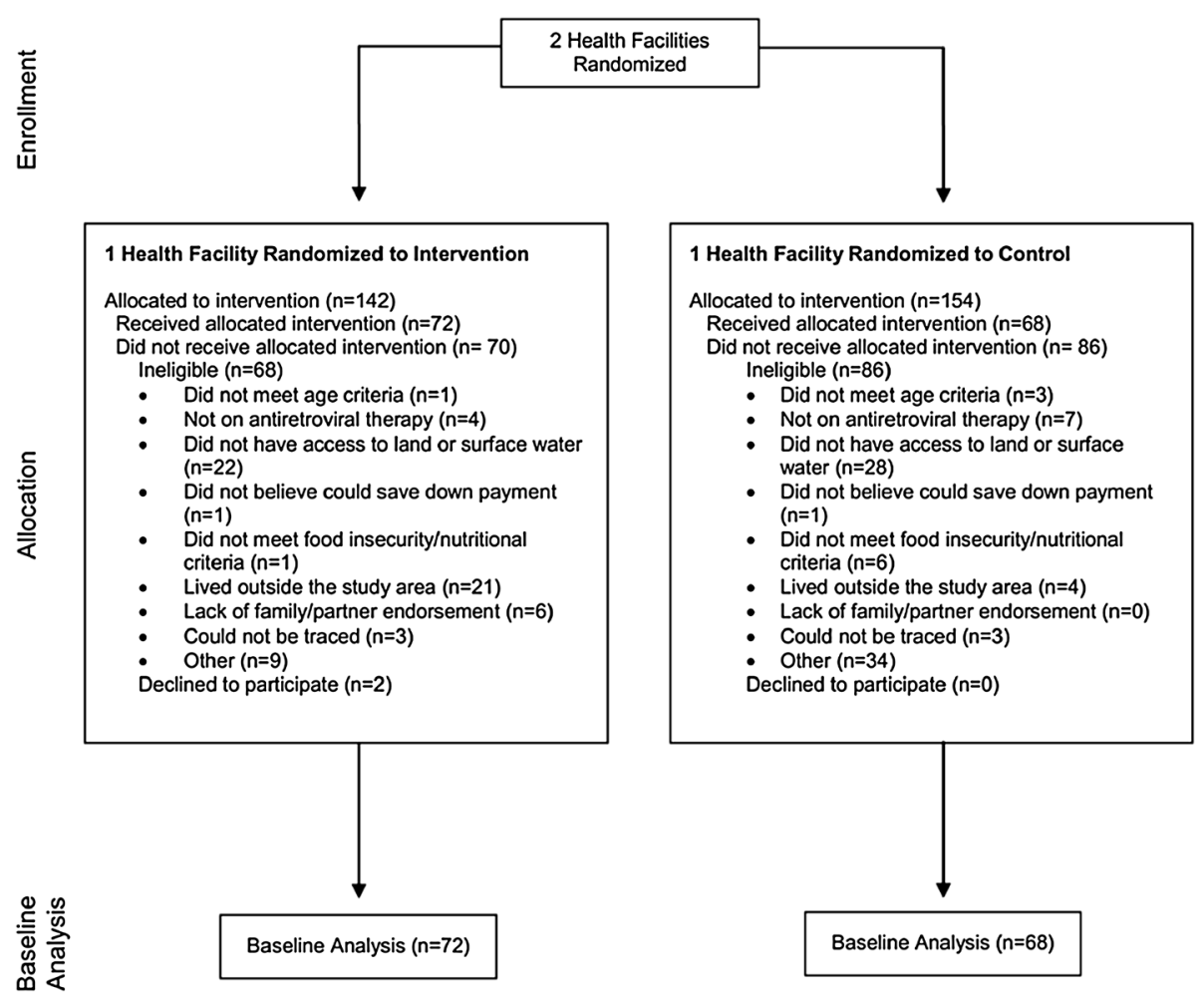

Figure 3 Shamba Maisha consort diagram 


Path
Nutritional Pathway

\section{Measurement}

Nutritional status

Food frequency

Behavioral Pathway

Pill count ART adherence

Competing demands

Healthcare access

Mental Health Pathway

Mental health \& depression

HIV-related stigma

Disclosure of HIV status

Alcohol use

\section{Empowerment}

Gender empowerment
Proximal Mediators

\section{Definition}

Nutritional status was assessed through body mass index (BMI) and mid-upper arm circumference (MUAC), commonly used to assess nutritional status (Physical Status 1995; Collins et al. 2000). The BMI reflects protein and fat reserves (James et al. 1988) and was assessed using an established grading system (Ferro-Luzzi et al. 1992). For MUAC, we used WHO sex-specific cut-offs of $22.0 \mathrm{~cm}$ for females and $23.0 \mathrm{~cm}$ for males with chronic energy deficiency (Doocy et al. 2005).

Food frequency, the number of different foods or food groups and the frequency consumed over a given reference period (Hoddinott \& Yohannes 2002), as adapted from the World Food Programme Food Consumption Score was collected.

Participants received an unannounced visit to inventory medications and count pills (Bangsberg et al. 2001a; Bangsberg et al. 2001 b; Bangsberg et al. 2000), a technique closely correlated with electronically monitored adherence, HIV viral load (Bangsberg et al. 2000) and progression to AIDS (Bangsberg et al. 2001c). The count of existing pills was reconciled with the participant's pharmacy refill history to determine the percentage of pills not yet consumed.

Questions were modified from Gelberg and Anderson's Behavioral Model for Vulnerable Populations (Gelberg et al. 2000; Gelberg et al. 1997) to assess how often lack of food interferes with ability to procure drugs or visit the clinic.

Utilization of health care services including hospitalizations and clinic visits over the preceding 6 months were collected.

Mental health status was measured using the Medical Outcomes Study HIV Health Survey (MOS-HIV), a tool for assessing health-related quality of life (Wu et al. 1991) that has been validated in resource-limited settings (Chatterton et al. 1999; Mast et al. 2004). Depression was screened using the Hopkins Symptom Check-list for depression, a 15-item scale (Derogatis et al. 1974) which has been validated in sub-Saharan Africa (Bolton et al. 2004).

We used the Internalized AIDS-Related Stigma Scale (Kalichman et al. 2009).

We asked about disclosure of HIV status to partners, family members, friends, colleagues, and public. These questions were adapted from our previous studies in Uganda, Botswana and Swaziland (Weise et al. 2007; Wolfe et al. 2008; Tsai et al. 2013).

To measure alcohol use, we adapted the Alcohol Use Disorders Identification Test (AUDIT-C) indicators. The AUDIT-C is a 3-item alcohol screen that can help identify persons who are hazardous drinkers or have active alcohol use disorders.

Empowerment indicators were adapted from a large cluster-randomized trial of an intervention including: greater challenges to established gender roles, communication with relationship partner about sexual matters in the prior 3 months, measures of financial decision-making, measures of attitudes towards gender roles and gender-based violence, and experience of controlling behavior by relationship partner in prior 3 months (Pronyk et al. 2006). In addition, we used the Sexual Relationship Power Scale (SRPS) (Pulerwitz et al. 2000), which conceptualizes sexual relationship power as a Power Scale (SRPS) (Pulerwitz et al. 2000), which conceptualizes sexual relationship power as a multi-dimensional construct consisting of relationship control and decision making dominance. The SRPS has been used successfully in observational research conducted in South Africa (Dunkle et al. 2004; Jewkes et al. 2010) and Uganda.(Weiser et al. 2010a, b) We also collected data on sexual victimization and perpetration in the prior 3 months.

The Household Food Insecurity Access Scale (HFIAS) has been validated in eight countries (Coates et al. 2006a; Swindale \& Bilinsky 2006; Frongillo \& Nanama 2006; Coates et al. 2006b) and used successfully by our team in rural Uganda. (Weiser et al. 2010a; Tsai et al. 2011; Weiser et al. 2012; Tsai et al. 2012; Weiser et al. 2010a, b; Miller et al. 2011; Tsai et al. 2011)
Frequency

Semi-annually

Quarterly

Quarterly

Semi-annually

Semi-annually

Semi-annually

Semi-annually

Semi-annually

Semi-annually

Semi-annually

Semi-annually 
Table 1 Measurements (Continued)

Agricultural measures

Agricultural measures were adapted from outcome evaluations developed by Kickstart in Kenya and supplemented by outcome indicators found in an earlier pilot study and a rural assessment. These measures were designed to evaluate uptake and adoption, and to measure changes in agricultural measures were designed to evaluate uptake and adoption, and to measure changes in agricultural
practices including crop diversity and agricultural practices and production. In addition, we evaluated practices including crop diversity and agricultural practices and production. In addition, we evaluated
the effectiveness of the training, and specific topics within, so as to refine the training for the subsequent the effectiveness of the training,

Household economic indicators

A modification of the World Bank Living Standards Measurement Study (LSMS) questionnaire (Grosh \& Glewwe 1998) was used to measure: a) expenditures (food, health, education and productive investments); b) consumption (food and non-food); c) income (from agriculture and all sources); and d) inter-household commodity and cash transfers.

The primary transmission risk outcome was unprotected sex. Other outcomes included: number of non-spousal/non-cohabiting sexual partners, sex-exchange (exchanging sex for money, food, or other resources) Dupas \& Robinson 2010); Robinson \& Yeh 2011)

Burial permits and information from family members were used to determine cause of death.

HIV-related mortality

Viral load suppression

CD4 Count

HIV morbidity

Physical health

Demographics

Social support

ART history and Self-reported ART adherence

Viral load testing was performed on venous blood on the COBAS TaqMan HIV viral load platform (Roche Molecular Diagnostics, Pleasanton, CA) with a lower limit of detection of $<20$ copies $/ \mathrm{mL}$.

We abstracted data for CD4 counts from participant's medical records. Absolute CD4 count testing was performed on whole blood using the BD FACSCount (BD Bioscience, San Jose, CA).

HIV morbidity was measured through key outcomes from the medical record. We abstracted data every 3 months for ART treatment interruptions and episodes of opportunistic infections. We also gathered self-report data on opportunistic infections and symptoms during structured interviews.

Health status was measured using the MOS-HIV, a tool for assessing health-related quality of life (Wu et al. 1991) that has been validated in resource-limited settings (Chatterton et al. 1999; Mast et al. 2004).

Age, religion, education, marital/partnership status, number of children and household census.

To measure social support, we adapted the Functional Social Support Scale (Antelman et al. 2001), a Higher scores reflect higher levels of social support.

Detailed ART history, ART self-reported adherence and barriers to ART adherence were collected. For self-report adherence, we used the visual analog scale (Oyugi et al. 2004) and the three day recall.
Quarterly

Quarterly

Semi-annually

As needed

Semi-annually

Semi-annually

Quarterly/Semi-annually

Semi-annually

Baseline modified version of the Duke University-University of North Carolina Functional Support Questionnaire (Broadhead et al. 1988) consisting of questions related to perceived emotional and instrumental support. 
(Table 1). Forms were later entered into the tablet using ODK Collect. Research assistants entered subsequent data directly into the tablet. Data for anthropometry (MUAC and BMI), and viral load results were entered into ODK Collect forms (Table 1). Medical history and CD4 determinations were abstracted from patient records and entered into the tablet (Table 1).

\section{Monitoring}

The study team conducted internal monitoring such as form completion and quality control of data entry monthly. Procedures to promote data quality including range and logical checks were built into the data entry program, and we ran a series of additional error checks on the databases following data entry. In addition, we used a rainfall gauge at the two study sites to record total precipitation by month.

\section{Process evaluation methods}

In order to understand the implementation successes and challenges, we conducted a detailed process evaluation alongside the Shamba Maisha trial. We interviewed 40 intervention participants and 20 key informants at two time points (3-5 months after study start and study end) to understand successes and challenges with implementation (for a total of $\mathrm{n}=120$ interviews). Interviews were conducted in English, Dhuluo or Kiswahili, and lasted between 45 minutes and 2 hours. We used a semi-structured interview guides to probe for feedback on recruitment and retention as well the key intervention components (the microcredit loan, the agricultural training, and the use of the hip pump), and elicit suggestions on how to improve each of these components. Interviews were transcribed verbatim and (as necessary) translated into English. Data were managed using Dedoose, (Dedoose Version 5.0.11 et al. 2014) a qualitative software that allows for real-time access to a secured database by a number of people in an analysis team. In line with previous qualitative process evaluations of complex interventions (Hargreaves et al. 2010), we used an inductive-deductive approach. First interviews were coded for broad themes by four researchers, using a structured coding framework developed from topics covered in the interview guide. Next, a second stage of inductive coding allowed sub-themes to emerge. Process evaluation findings are used to suggest how these might help refine the intervention in a future trial.

\section{Statistical methods}

For this baseline manuscript, we compared baseline characteristics between participants enrolled in the intervention and control sites using proportions for categorical variables and means or medians (as appropriate) for continuous variables. An assessment of the distribution (normally or skewed) of continuous variables was performed. Statistical tests for descriptive analyses included chi-square tests for categorical variables, and Wilcoxon rank-sum or t-tests and for continuous variables.

\section{Analysis of outcome data}

This pilot was not powered for formal significance testing of the intervention effect on primary health, behavioral and gender empowerment outcomes. Rather, analyses will focus on assessing the effects of the intervention on proximal mediating factors (Figure 2), and separately on primary outcomes. Analyses for mediating variables will generally treat scores as continuous measures. For example, food security will be measured using the Household Food Insecurity Access Scale (HFAIS) score at the 1-year visit; change in household economic indicators over the 1-year follow-up period will be measured by subtracting baseline from 1-year follow-up data for household expenditures, consumption and income (from agricultural and other sources). Initial comparisons will be based on group-specific descriptive summaries of observed outcomes and rank-based tests comparing outcomes between groups. We will also use regression methods to compare outcomes between groups and control for baseline characteristics. Analyses for primary health outcomes will proceed similarly, with appropriate choices of model for outcome type. For example, we will use pooled logistic regression for between-group comparisons of rates of viral load suppression, and mixed effects regression to compare changes in CD4 counts between groups. We will also make preliminary assessments of degree of mediation in models for primary outcomes via inclusion of mediating factors, with assessment of direct and indirect intervention effects of key mediating variables (Petersen et al. 2006). Finally, we will also perform intent-to-treat and per-protocol analyses of the pilot data, with the per-protocol subset limited to participants that obtained and used the intervention consistently over the 12-months of follow-up. Although these analyses will likely be underpowered for formal testing purposes, the resulting estimates and confidence intervals will be important for planning for the subsequent RCT.

\section{Results}

\section{Screening and enrollment}

Figure 3 describes study screening and enrollment numbers, along with reasons for participant ineligibility. We screened 142 and 154 adults, respectively at the intervention and control sites. We enrolled 72 and 68 participants at the intervention and control sites, respectively; four participants withdrew from the study, 
four from the intervention site and zero from the control site. One participant in the intervention arm failed to save the down payment necessary to receive the loan and was subsequently withdrawn from the study. The most common reasons for study ineligibility of screened participants included: did not have access to land or surface water, lived outside the study area, not on ART, and "other" reasons.

\section{Baseline characteristics of participants}

At baseline (Table 2) participants at the intervention and control sites, respectively were similar in age (37 vs. 38 years), gender (51\% female in both), education (19\% vs. $18 \%$ completed secondary school) and marital status (75\% vs. $79 \%$ married). Mental health and gender empowerment measures were similar among participants enrolled at the intervention and control sites. Reported monthly household income was lower among participants enrolled at the intervention in comparison to the control site $(\sim 104)$ vs. $(\sim 273), \mathrm{p}=0.008)$.

A similar proportion of participants at the intervention and control sites reported moderate and severe food insecurity based on the HFAIS, although a greater proportion of participants at the intervention site had a low BMI in comparison to participants at the control site $(18 \%$ vs. $7 \%, \mathrm{p}=0.054)$ (Table 2$)$. In regards to dietary intake, participants enrolled at the intervention site reported less frequency of vegetable, meat/poultry, dairy, cooking fat, and sweets than participants enrolled at the control site (Table 2).

Twenty-one percent and 33\%, respectively of intervention and control site participants had WHO stage 3 or 4 disease. While median CD4 count was similar between arms (intervention: 446 cells $/ \mathrm{mm}^{3}$ vs. control: 475 cells/ $\mathrm{mm}^{3}, \mathrm{p}=0.33$ ), a greater proportion of participants enrolled at the intervention arm had a detectable HIV viral load than participants enrolled at the control arm ( $49 \%$ vs. $28 \%$, respectively, p < 0.010 ); Self-reported ART adherence $<90 \%$ per visual analogue scale was rare in both arms of the trial (Table 2).

\section{Implementation successes and challenges}

A variety of implementation successes and challenges were documented during the qualitative process evaluation. Positive aspects of Shamba Maisha included high acceptability during recruitment, successes with agricultural and financial training, and labor savings from using the pump. Implementation challenges included considerable concern about repaying loans, agricultural and irrigation challenges related to weather patterns, and a challenging partnership with the microfinance institution.

\section{Successes with Shamba Maisha implementation}

1) Strong willingness to join. Nearly all participants interviewed expressed a strong interest in taking part in Shamba Maisha. Many had expectations that this intervention would improve their households and lives as expressed by one participant:

What motivated me more to join the project was the training that they were coming to train us, they gave us some very good training. So when I heard about the type of training, the targets they put for us and the amount of money we would get... that if we got it then life would change for the better. (Male participant, 3 months, 31 years old).

2) Excellent agricultural training. The agricultural portion of the training was a success and participants noted positive impacts even before they received the agricultural inputs, including increased and diversified crop production. The newly acquired farming skills were discussed with great pride by participants. The agricultural techniques resulted in larger harvests from smaller pieces of land - an outcome that many participants cherished:

Before Shamba Maisha we just used to farm very huge pieces of land and get very small harvests. From the training we realized that we are able to farm a small piece of land and get a bumper harvest. This was really an eye opener for us. (Female participant, 3 months, 42 years old).

Another woman explained crucial techniques around plowing, ridge planting, and nursery beds:

We were taught on how to farm in order to get something good; for you to realize a good harvest, you need to plough deeply, then break it into more fine particles. Then you make ridges that we were given to help us in making the seedbeds and nursery. You make the nursery then plant them then later transfer then to the main farm. (Female participant, 3 months, 45 years old).

Some participants even explained how neighbors were drawn to them as a result of the improved techniques:

Because of Shamba Maisha, I was able to embrace a modern way of farming that has attracted people from all over to come and learn from it. (Male participant, 12 months, 44 years old). 
Table 2 Comparison of baseline sociodemographic, economic, sexual risk behavior, dietary intake, clinical, mental health, gender empowerment, clinical and laboratory findings of participants enrolled in Shamba Maisha at the intervention and control sites

\begin{tabular}{|c|c|c|c|}
\hline & $\begin{array}{l}\text { Intervention } \\
\mathrm{N}=72\end{array}$ & $\begin{array}{l}\text { Control } \\
N=68\end{array}$ & P-value \\
\hline Sociodemographic variables & n (\%) & n (\%) & \\
\hline Mean age in years (SE) & $37(0.80)$ & $38(0.80)$ & 0.16 \\
\hline Female gender & $37(51)$ & $35(51)$ & 0.92 \\
\hline Education $\geq$ secondary school & $14(19)$ & $12(18)$ & 0.82 \\
\hline Current married & $54(75)$ & $54(79)$ & 0.25 \\
\hline Mean number of people in household (SE) & $6(0.2)$ & $7(0.3)$ & 0.12 \\
\hline \multicolumn{4}{|l|}{ Food security level } \\
\hline Moderately food insecure & $14(20)$ & $14(21)$ & 0.86 \\
\hline Severely food insecure & $57(80)$ & $53(78)$ & 0.86 \\
\hline Body Mass Index (BMI) $<18.5$ & $13(18)$ & $5(7)$ & 0.054 \\
\hline \multicolumn{4}{|l|}{ Economic indicators } \\
\hline Mean (SE) Monthly Household Income (USD*) & $104(21.3)$ & $273(53.1)$ & 0.008 \\
\hline Land ownership (Self or Jointly) & $60(83)$ & $49(73)$ & 0.14 \\
\hline \multicolumn{4}{|l|}{ Sexual risk behavior } \\
\hline Any unprotected sex & $13(18)$ & $12(18)$ & 0.95 \\
\hline Sex exchange (ever) & $15(21)$ & $28(41)$ & 0.009 \\
\hline Sex exchange (last 3 months) & $2(3)$ & $6(9)$ & 0.12 \\
\hline$>1$ Sexual partners in the past 3 months & $9(13)$ & $9(13)$ & 0.92 \\
\hline \multicolumn{4}{|l|}{ Dietary intake (frequency of consumption - times/week) } \\
\hline Grains mean (SE) & $19.0(0.8)$ & $20.8(0.8)$ & 0.1320 \\
\hline Vege`s mean (SE) & $20.3(0.9)$ & $25.9(0.7)$ & $<0.0001$ \\
\hline Fruit mean (SE) & $9.0(0.6)$ & $10.6(0.9)$ & 0.1352 \\
\hline Meat, Poultry mean (SE) & $3.4(0.3)$ & $5.3(0.3)$ & $<0.00001$ \\
\hline Eggs mean (SE) & $0.9(0.1)$ & $1.3(0.2)$ & 0.117 \\
\hline Dairy mean (SE) & $1.9(0.3)$ & $4.5(0.5)$ & $<0.0001$ \\
\hline Cooking fat mean (SE) & $5.0(0.3)$ & $6.8(0.1)$ & $<0.00001$ \\
\hline Sweets mean (SE) & $7.1(0.7)$ & $11.9(0.7)$ & $<0.00001$ \\
\hline \multicolumn{4}{|l|}{ Mental health } \\
\hline Depression score $\geq 1.75$ (clinical depression) & $1(1)$ & $4(6)$ & 0.2 \\
\hline Mental health summary score (SE) & $57.1(3.4)$ & $42.8(5.6)$ & 0.15 \\
\hline Mean internalized AIDS related stigma scale (SE) & $14.1(0.2)$ & $13.7(0.2)$ & 0.19 \\
\hline Disclosed to husband/wife/partner & $65(97)$ & $63(95)$ & 0.68 \\
\hline Mean Social Support Score (SE) & $53.4(10.8)$ & $35.8(8.3)$ & 0.2 \\
\hline Problem drinking based on audit $C$ & $1(1)$ & $2(3)$ & 0.53 \\
\hline \multicolumn{4}{|l|}{ Gender empowerment } \\
\hline Mean sexual relationship power scale (women only) (SE) & $54(10)$ & $47(8)$ & 0.59 \\
\hline Mean decision making dominance scale (SE) & $46(5)$ & $42(4)$ & 0.46 \\
\hline \multicolumn{4}{|l|}{ Clinical, Laboratory and antiretroviral (ART) adherence } \\
\hline WHO clinical stage 3 or 4 & $15(21)$ & $22(33)$ & 0.12 \\
\hline Median CD4 (IQR) cells $/ \mathrm{mm}^{3}$ & $446(330-629)$ & $475(356-679)$ & 0.33 \\
\hline Baseline CD4 $\leq 350$ cells $/ \mathrm{mm}^{3}$ & $20(29)$ & $16(24)$ & 0.467 \\
\hline Viral load above the limit of detection ( $\geq 20$ copies $/ \mathrm{mL}$ ) & $34(49)$ & $19(28)$ & 0.010 \\
\hline Physical health summary score (SE) & $54.3(3.6)$ & $45.5(4.0)$ & 0.03 \\
\hline Hospitalized in the last three months & $3(4)$ & $5(7)$ & 0.4 \\
\hline Reported ART adherence per Visual Analogue Scale $<90 \%$ & $0(0)$ & $6(9)$ & 0.01 \\
\hline
\end{tabular}

*Converted Kenyan shillings (Ksh) to US dollar (85 Ksh/\$). 
3) Bolstering financial skills. Some participants spoke of the utility of financial trainings, in particular the lessons around savings and record keeping:

On savings we learnt a lot from the leader on the microfinance team on how we can save in the bank, we also learnt on record keeping while farming and how we can build our lives relying on the trainings... That was very good. (Male participant, 3 months, 38 years old).

4) Ease of irrigation with water pumps. For a number of Shamba Maisha participants, the pump was easier to implement than previous irrigation strategies, such as bucket irrigation, leading to labor savings.

I use the pump with a well. It helps in irrigation, at the times when these things need water I can use it. And I find it to be easier as compared to how I could have done it in the past where I could have taken maybe a bucket and use it to pour water. (Male participant, 3 months, 33 years old).

Before I used to fetch water from the borehole then I used a calabash to pour water directly. But now once I get two people, I just take the machine and pump water straight from the water source and irrigate just by pressing. So I use less energy in irrigation unlike before. (Male participant, 12 months, 44 years old).

\section{Barriers to Shamba Maisha implementation}

Despite these successes during implementation, participants noted a number of challenges, and had some recommendation for improving the intervention.

1) Fear of loan repayment. Some participants talked about the loan repayment as a potentially discouraging aspect of the intervention:

We were going to be given loan and we'd be expected to repay some money back. This discouraged people and it's still a factor that continue to discourage others... here in Luo, they are scared of 'debt recoveries". (Male participant, 3 months, 43 years old).

2) Lack of choice in how to use loan. While many were satisfied with the commodities provided as part of Shamba Maisha, some suggested that to improve the intervention, Shamba Maisha should provide the loan but allow people to decide how best to use it. For example, one man spoke about preference for livestock over farming:
Farming, it is very difficult and requires you to take a lot of time, because people like us if you are doing it, it is something that you do full time. But we were thinking that if there was a different way other than farming, if one could choose what he could do then I think it could be better. ... If I was told to choose then I would prefer to be given a cow, because that is something that I know and I have had some experience with. (Male participant, 3 months, 35 years old).

Another participant wished for crops that were less perishable so that they can be stored and sold when the market was better:

In my own view to help people more, if we could be introduced to a new type of farming or crop, that could uplift us because vegetables are little in terms of production and also are very perishable. So if you can introduce some new crops that even after harvesting can be stored until they fetch a good price in the market. You can keep them and later decide on the quantity to sell to repay the loan. (Female, 12 months, 40 years old).

3) Agricultural Challenges. While agricultural productivity was reported to have improved by the majority of participants, variability in weather patterns impacted crop production throughout the course of the study period and across the communities. There were periods of flooding and hail storms which adversely affected crop production. For example, one woman complained of weather-related crop damage, despite describing having been very well trained to farm in the program "All my crops have been destroyed by the hailstorm and I have no means of repaying the loan." (Female participant, 3 months, 38 years old) Rain gauges were used to monitor precipitation at the district hospitals in the intervention and control communities. Annual rainfall was reported to be higher than normal over the course of the one-year intervention with extended rainy seasons. As a result, the irrigation technology was not utilized as much as expected, decreasing some of the potential advantages.

Irrigation is good, though we haven't embraced it to an extent that it can fully benefit us because when we started it...the rain started. Our pumps are not being used because currently it's rainy season and you can't really sow vegetable seeds when there is too much rain. (Male participant, 12 months, 44 years old).

4) Pump Challenges. Although most participants reported that the pumps were easy to use, some male and female participants had difficulty operating the pumps on their own. 
As described by one participant:

It is impossible to operate it comfortably as an individual. It demands that it is operated by two or three people with one person pumping the water as one directs the pipe to the shamba [farm]. When I used it, my sons had to assist me. (Female participant, 3 months, 30 years old).

5) Challenges with Microfinance Institution. The local microfinance organization selected for the study had poor governance and was unable to fulfill the obligations of the study. Specifically, there were significant delays in dispersal of the loans and fiscal insolvency, leading to the closure of the local branch:

It [The microfinance organization] could be closed for even 3 months. You go there and find the offices are closed and sometimes your money is in there...so it leaves you with a lot of doubts...And that is the main reason why many people ended up having fears that their money would get lost here. (Male participant, 3 months, 28 years old).

Based on this finding, which emerged early in the process evaluation data collection, study leadership terminated the partnership with Adok Timo and transferred the loans to a local NGO which managed the loan collection for the remainder of the study period.

\section{Discussion}

This pilot study was designed to determine the acceptability and feasibility of the intervention and control conditions, and to determine the preliminary impact of the intervention on mediating outcomes (food security, and household economic indicators). In the baseline evaluation of Shamba Maisha, we demonstrated that screening and enrollment into the intervention and control groups was rapid. Enrollment of the 140 participants took only four months, and the screening to enrollment ratio was similar between study arms. Thus, patients at the two study facilities were interested to screen and enroll in the study, i.e. enrollment into the control conditions did not appear to mitigate interest in study participation. This finding has important implications in regards to feasibility for advancing the intervention into a phase 3 cluster randomized controlled trial.

We found that the participants in the intervention and control groups were relatively similar demographically. However, participants at the control site reported a higher household income and dietary intake of vegetables and various protein sources. Importantly, participants in the control group were more likely to have an HIV-1 viral load below the limit of detection than participants enrolled in the intervention group. Self-reported ART non-adherence was uncommon in both groups. The lower proportion of non-detectable plasma viral loads in the intervention group may be related to the fact that the intervention group was economically worse off at baseline, and other studies have shown that markers of lower socioeconomic status are associated with delayed entry into care and worse HIV outcomes. In prior clinical programs in sub-Saharan Africa, viral load suppression ranges from $18 \%-41 \%$ in observational studies (Hassan et al. 2014; Liegeois et al. 2012; Anude et al. 2013). Thus, our findings are relatively consistent with these results. Of note, this pilot study was not powered or designed to detect differences in viral load suppression by study arm. Rather the future trial will address variability and heterogeneity by randomizing approximately eight matched pair cluster (16 sites). We plan to match sites on a variety of criteria including sociodemographic factors, average rainfall, soil type, access to predominant source of surface water for irrigation (lake, vs. river, vs. shallow wells) and facility type (dispensary, vs. health center, vs. hospital).

Process evaluations garner in-depth knowledge around implementing complex interventions, which aids both interpretation of trial findings and informs potential replication (Oakley et al. 2006). Our process evaluation suggested robust acceptability of the Shamba Maisha intervention and trial, which aligns with the nearly $100 \%$ follow-up rate for both intervention and control participants at trial close. We also found that agricultural and financial training has strong advantages on their own, and that training should be integral to successful microfinance organizations. As anticipated, our qualitative data suggest that the microirrigation intervention can be laborsaving.

We also had significant challenges, most notably with regard to the microfinance component of the intervention. The partnering microfinance institution was unreliable, insolvent, and had a local branch closure during the trial. This is perhaps not surprising, given that past attempts to offer microfinance alongside HIV-related activities have experienced major challenges (Epstein 2006; Gregson et al. 2007). Researchers from the IMAGE intervention concluded that a strong microfinance partnership is indeed a pre-requisite to sustainably scaling this type of multisectoral intervention (Hargreaves et al. 2011). Thus, the replication of this trial in a larger setting should entail partnering with a microfinance institution that is financially stable and whose business model can accommodate Shamba Maisha. Participant concerns around loan repayment are an important 
ethical consideration; particularly in light of recent findings that microfinance may fail to provide enough income for financially disadvantaged households (Stewart et al. 2010; Barnes et al. 2001; Kaboski \& Townsend 2008). As a result, we plan to consult local and global experts in microfinance in order to ensure that this component meets the needs of the study, and is designed with the potential for scale-up and sustainability is similar settings in East Africa.

These findings should be considered in light of design limitations. The pilot cluster-randomized design included two sites, and thus will need to be replicated in a larger cluster randomized trial. Second, qualitative process evaluations may suffer from respondent bias, particularly if participants held the impression that researchers were part of the intervention delivery team. We attempted to address this shortcoming by hiring separate in-depth interviewers that were not part of the primary study team. Lastly, the challenges with our microfinance organization made it difficult to assess the full potential of that component of the intervention.

We expect the pilot study will provide critical new evidence regarding the implementation of a multisectoral agricultural intervention aimed to improve food insecurity, household economic indicators and health among HIV-infected persons in rural Kenya. Following evaluation of the quantitative and qualitative results from this study, we plan to scale up this pilot to a cluster randomized trial to definitively assess the effectiveness of this intervention on the health of PLHIV using ART.

\section{Abbreviations}

ART: Antiretroviral therapy; ARV: Antiretrovirals; AUDIT-C: Alcohol Use Disorders Identification Test; BMI: Body mass index; FACES: Family AIDS Care \& Education Services; HFAIS: Household Food Insecurity Access Scale; KEMRI: Kenyan Medical Research Institute; IPM: Integrated pest and disease management; MOS-HIV: Medical Outcomes Study HIV Health Survey; MUAC: Mid upper arm circumference measurements; NGO: Non-governmental organization; ODK: Open Data Kit; PLHIV: People living with HIV/AIDS; RCT: Randomized controlled trial; SRPS: Sexual Relationship Power Scale; UCSF: University of California, San Francisco.

\section{Competing interest}

The authors declare that they have no competing interests.

\section{Authors' contributions}

Conceived and designed the experiments: CRC, SDW, EAB. Performed the experiments: EW, RLS. Analyzed the data: FW, SS, CRC, SDW, RLS, AMH, RR, KS, SLD. Wrote the paper: CRC, SW, RLS, EW, AH. Contributed to the writing of the manuscript: CRC, SDW, RLS, EW, EAB, LMB. All authors read and approved the final manuscript.

\section{Acknowledgements}

We thank the Kenyan men and women who are participating in the study. We acknowledge the important logistical support of the KEMRI-UCSF Collaborative Group and especially FACES. We gratefully acknowledge the Director of KEMRI, the Director of KEMRI's Centre for Microbiology Research, and the Nyanza Provincial Ministries of Health for their support in conducting this research. We also thank Beatrice Otieno, Nolline Akuku, Clare Aloo, Jackline Atieno, Perez Kitoto, Mark Matinde, Nicholas Otieno, Pamela Omondi, and Amos Onyang for their important contributions to this research.

\section{Funding}

The research described was supported by the National Institutes of Mental Health. The study was funded under grant 1R34MH094215. The funders had no role in data collection and analysis.

\section{Author details}

${ }^{1}$ Department of Obstetrics, Gynecology \& Reproductive Sciences, University of California San Francisco, 550 16th Street, San Francisco, CA 94158, USA.

${ }^{2}$ Departments of Medicine, University of California San Francisco, San Francisco, CA, USA. ${ }^{3}$ Departments of Epidemiology and Biostatistics, University of California San Francisco, San Francisco, CA, USA. ${ }^{4}$ Departments of Social and Behavioral Sciences, University of California San Francisco, San Francisco, CA, USA. ${ }^{5}$ Center of Expertise in Women's Health \& Empowerment, University of California Global Health Institute, San Francisco, CA, USA. ${ }^{6}$ Centre for Microbiology Research, Kenya Medical Research Institute, Nairobi, Kenya. ${ }^{7}$ Centre for Clinical Research, Kenya Medical Research Institute, Nairobi, Kenya. ${ }^{8}$ Department of Environmental and Global Health, University of Florida, Gainesville, FL, USA. ${ }^{9}$ Department of Soil Science and Soil Microbial Biology, University of California Davis, Davis, CA, USA. ${ }^{10}$ Wits Reproductive Health and HIV Institute, University of the Witwatersrand, Johannesburg, South Africa. "11Boston Children's Hospital and Harvard Medical School, Boston, MA, USA.

Received: 3 September 2014 Accepted: 13 February 2015

Published online: 12 March 2015

\section{References}

About KickStart [http://www.kickstart.org/about-us/]

Agricultural initiatives for health in Haiti, Rwanda, and Lesotho

Anema A, Weiser SD, Fernandes KA, Brandson EK, Montaner JS, Hogg RS (2011) High prevalence of food insecurity among HIV-infected individuals receiving HAART in a resource-rich setting. AIDS Care 23(2):221-230

Antelman G, Smith Fawzi MC, Kaaya S, Mbwambo J, Msamanga Gl, Hunter DJ, Fawzi WW (2001) Predictors of HIV-1 serostatus disclosure: a prospective study among HIV-infected pregnant women in Dar es Salaam. Tanzania AIDS 15(14):1865-1874

Anude CJ, Eze E, Onyegbutulem HC, Charurat M, Etiebet MA, Ajayi S, Dakum P, Akinwande O, Beyrer C, Abimiku A, Blattner W (2013) Immunovirologic outcomes and immuno-virologic discordance among adults alive and on anti-retroviral therapy at 12 months in Nigeria. BMC Infect Dis 13:113

Ashburn K, Kerrigan D, Sweat M (2008) Micro-credit, women's groups, control of own money: HIV-Related negotiation among partnered Dominican women. AIDS behav 12(3):396-403

Babameto G, Kotler DP (1997) Malnutrition in HIV infection. Gastroenterol Clin North Am 26(2):393-415

Bangsberg DR, Hecht FM, Charlebois ED, Zolopa AR, Holodniy M, Sheiner L, Bamberger JD, Chesney MA, Moss A (2000) Adherence to protease inhibitors, HIV-1 viral load, and development of drug resistance in an indigent population. AIDS 14(4):357-366

Bangsberg DR, Hecht FM, Charlebois ED, Chesney MA, Moss A (2001a) Comparing objective measures of adherence to HIV antiretroviral therapy: Electronic medication monitors and unannounced pill counts. AIDS Behav 5:275-281

Bangsberg DR, Hecht FM, Clague H, Charlebois ED, Ciccarone D, Chesney M, Moss A (2001b) Provider assessment of adherence to HIV antiretroviral therapy. J Acquir Immune Defic Syndr 26(5):435-442

Bangsberg DR, Perry S, Charlebois ED, Clark RA, Roberston M, Zolopa AR, Moss A (2001c) Non-adherence to highly active antiretroviral therapy predicts progression to AIDS. AIDS 15(9):1181-1183

Bardsley-Elliot A, Plosker GL (2000) Nelfinavir: an update on its use in HIV infection. Drugs 59(3):581-620

Barnes C, Keogh E, Nemarundwe N (2001) Microfinance program clients and impact: An assessment of Zambuko Trust, Zimbabwe. AIMS, Washington, DC

Blumberg SJ, Dickey WC (2003) Prevalence of HIV risk behaviors, risk perceptions, and testing among US adults with mental disorders. J Acquir Immune Defic Syndr 32(1):77-79

Bolton P, Wilk CM, Ndogoni L (2004) Assessment of depression prevalence in rural Uganda using symptom and function criteria. Soc Psychiatry Psychiatr Epidemiol 39(6):442-447 
Brandsma T (2003) Waterworks: Kenyan Farmers Are Getting A Big Boost From A Simple Piece Of Equipment. In: Newsweek. [http://www.newsweek.com/ waterworks-137625]

Broadhead WE, Gehlbach SH, de Gruy FV, Kaplan BH (1988) The Duke-UNC Functional Social Support Questionnaire Measurement of social support in family medicine patients. Med Care 26(7):709-723

Byron E, Gillespie S, Nangami M (2008) Integrating nutrition security with treatment of people living with HIV: lessons from Kenya. Food Nutr Bull 29(2):87-97

Campbell AA, de Pee S, Sun K, Kraemer K, Thorne-Lyman A, Moench-Pfanner R, Sari M, Akhter N, Bloem MW, Semba RD (2009) Relationship of household food insecurity to neonatal, infant, and under-five child mortality among families in rural Indonesia. Food Nutr Bull 30(2):112-119

Cantrell RA, Sinkala M, Megazinni K, Lawson-Marriott S, Washington S, Chi BH, Tambatamba-Chapula B, Levy J, Stringer EM, Mulenga L, Stringer JSA (2008) A pilot study of food supplementation to improve adherence to antiretroviral therapy among food-insecure adults in Lusaka Zambia. J Acquir Immune Defic Syndr 49(2):190-195

Chatterton ML, Scott-Lennox J,

Wu AW, Scott J (1999) Quality of life and treatment satisfaction after the addition of lamivudine or lamivudine plus loviride to zidovudine-containing regimens in treatment-experienced patients with HIV infection. Pharmacoeconomics 15(Suppl 1):67-74

Coates J, Swindale A, Bilinsky P (2006a) Household Food Insecurity Access Scale (HFIAS) for Measurement of Food Access: Indicator Guide. Food and Nutrition Technical Assistance. Academy for Educational Development, Washington, D.C, pp 1-30

Coates J, Frongillo EA, Rogers BL, Webb P, Wilde PE, Houser R (2006b) Commonalities in the experience of household food insecurity across cultures: what are measures missing? J Nutr 136(5):1438S-1448S

Collins C, Duffield A, Myatt M (2000) Adults Assessment of Nutritional Status in Emergency-Affected Populations In. United Nations, Administrative Committee on Coordination, Sub-committee on Nutrition, Geneva, Switzerland, pp 1-28

Dedoose Version 5.0.11, web application for managing, analyzing, and presenting qualitative and mixed method research data (2014). Los Angeles, CA: SocioCultural Research Consultants LLC.

Derogatis LR, Lipman RS, Rickels K, Uhlenhuth EH, Covi L (1974) The Hopkins Symptom Checklist (HSCL) A measure of primary symptom dimensions. Mod Probl Pharmacopsychiatry 7:79-110

Diagne A (1998) Impact of Access to Credit on Income and Food Security in Malawi. CND Discussion Paper No 46. International Food Policy Research Institute, Washington, D.C

Doocy S, Teferra S, Norell D, Burnham G (2005) Credit program outcomes: coping capacity and nutritional status in the food insecure context of Ethiopia. Soc Sci Med 60(10):2371-2382

Dunkle KL, Jewkes RK, Brown HC, Gray GE, McIntryre JA, Harlow SD (2004) Gender-based violence, relationship power, and risk of HIV infection in women attending antenatal clinics in South Africa. Lancet 363(9419):1415-1421

Dupas P, Robinson J (2010) Coping with political instability: micro evidence from Kenya's 2007 election crisis. Am Econ Rev 100(2):120-124

Dworkin SL, Blankenship K (2009) Microfinance and HIV/AIDS prevention: assessing its promise and limitations. AIDS Behav 13(3):462-469

Epstein H (2006) The underground economy of AIDS. Virginia Quart Rev 82(1):53-63

Evans DL, Ten Have TR, Douglas SD, Gettes DR, Morrison M, Chiappini MS, Brinker-Spence P, Job C, Mercer DE, Wang YL, Cruess D, Dube B, Dalen EA, Brown T, Bauer R, Petitto JM (2002) Association of depression with viral load, CD8 T lymphocytes, and natural killer cells in women with HIV infection. Am J Psychiatry 159(10):1752-1759

Food and Agriculture Organization (2010a) The State of Food Insecurity in the World-Addressing Food Insecurity in Protracted Crises. Food and Agriculture Organization of the United Nations, Rome

Ferro-Luzzi A, Sette S, Franklin M, James WP (1992) A simplified approach of assessing adult chronic energy deficiency. Eur J Clin Nutr 46(3):173-186

Fields-Gardner C, Fergusson P (2004) Position of the American Dietetic Association and Dietitians of Canada: nutrition intervention in the care of persons with human immunodeficiency virus infection. J Am Diet Assoc 104(9):1425-1441
Food and Agriculture Organization (2010b) The State of Food Insecurity in the World_Addressing Food Insecurity in Protracted Crises. Food and Agriculture Organization of the United Nations, Rome

Food and Nutrition Technical Assistance. HIV/AIDS: A Guide For Nutritional Care and Support [http://www.fantaproject.org/publications/HIVguide.shtml]

Frongillo EA, Nanama S (2006) Development and validation of an experience-based measure of household food insecurity within and across seasons in northern Burkina Faso. J Nutr 136(5):1409S-1419S

Gelberg L, Gallagher TC, Andersen RM, Koegel P (1997) Competing priorities as a barrier to medical care among homeless adults in Los Angeles. Am J Public Health 87(2):217-220

Gelberg L, Andersen RM, Leake BD (2000) The Behavioral Model for Vulnerable Populations: application to medical care use and outcomes for homeless people. Health Serv Res 34(6):1273-1302

Global report (2013) UNAIDS report on the global AIDS epidemic. Joint United Nations Programme on HIV/AIDS, Geneva Switzerland

Gomez B, Lister A, Wiese M (2004) Micro-credit: giving life through work to PLWHA. International AIDS Conference: 2004, Bangkok, Thailand

Goudge J, Ngoma B (2011) Exploring antiretroviral treatment adherence in an urban setting in South Africa. J Public Health Policy 32(Suppl 1):S52-S64

Government of Kenya (2008) District Development Plan: Migori. District Commissioner's Office, Government of Kenya, Migori, Kenya

Gregson S, Adamson S, Papaya S, Mundondo J, Nyamukapa CA, Mason PR, Garnett GP, Chandiwana SK, Foster G, Anderson RM (2007) Impact and Process Evaluation of Integrated Community and Clinic-Based HIV-1 Control: A Cluster-Randomised Trial in Eastern Zimbabwe. PLoS Medicine 4(3):e102

Grosh M, Glewwe P (1998) Data Watch: the World Bank's Living Standard Measurement Study household surveys. J Econ Perspect 12(1):187-196

Gustavson L, Lam W, Bertz R, Hsu A, Rynkiewicz K, Ji Q, Ghosh S, Facey I, Bernstein B, Sun E (2000) Assessment of the bioequivalence and food effects for liquid and soft gelatin capsule co-formulations of ABT-378/ritonavir (ABT-378/r) in healthy subjects. 40th Interscience Conference on Antimicrobial Agents and Chemotherapy: 2000, Toronto, Canada

Hargreaves J, Hatcher A, Strange V, Phetla G, Busza J, Kim J, Watts C, Morison L, Porter J, Pronyk P, Bonnell C (2010) Process evaluation of the Intervention with Microfinance for AIDS and Gender Equity (IMAGE) in rural South Africa. Health Educ Res 25(1):27-40

Hargreaves J, Hatcher A, Busza J, Strange V, Phetla G, Kim J, Watts C, Porter JD, Pronyk P, Bonell C (2011) What happens after a trial? Replicating a cross-sectoral intervention addressing the social determinants of health: the case of the Intervention with Microfinance for AIDS and Gender Equity (IMAGE) in South Africa. In: Blas E, Sommerfeld J, Kurup AS (eds) Social determinants approaches to public health. World Health Organization, Geneva, pp 147-159

Hassan AS, Nabwera HM, Mwaringa SM, Obonyo CA, Sanders EJ, de Wit Rinke TF, Cane PA, Berkley JA (2014) HIV-1 virologic failure and acquired drug resistance among first-line antiretroviral experienced adults at a rural HIV clinic in coastal Kenya: a cross-sectional study. AIDS Res Ther 11(1):9

Hatcher AM, Tsai AC, Kumbakumba E, Dworkin SL, Hunt PW, Martin JN, Clark G, Bangsberg DR, Weiser SD (2012) Sexual relationship power and depression among HIV-infected women in Rural Uganda. PLoS One 7(12):e49821

Hiarlaithe MO, Grede N, de Pee S, Bloem M (2014) Economic and Social Factors are Some of the Most Common Barriers Preventing Women from Accessing Maternal and Newborn Child Health (MNCH) and Prevention of Mother-to-Child Transmission (PMTCT) Services: A Literature Review. AIDS Behav 18 Suppl 5:S516-S530

Hoddinott J, Yohannes Y (2002) Dietary diversity as a household food security indicator. Food and Nutrition Technical Assistance Project, Academy for Educational Development, Washington, D.C

Ickovics JR, Hamburger ME, Vlahov D, Schoenbaum EE, Schuman P, Boland RJ, Moore J (2001) Mortality, CD4 cell count decline, and depressive symptoms among HIV-seropositive women: longitudinal analysis from the HIV Epidemiology Research Study. JAMA 285(11):1466-1474

James WP, Ferro-Luzzi A, Waterlow JC (1988) Definition of chronic energy deficiency in adults Report of a working party of the International Dietary Energy Consultative Group. Eur J Clin Nutr 42(12):969-981

Jewkes RK, Dunkle K, Nduna M, Shai N (2010) Intimate partner violence, relationship power inequity, and incidence of HIV infection in young women in South Africa: a cohort study. Lancet 376(9734):41-48 
Johannessen A, Naman E, Ngowi BJ, Sandvik L, Matee MI, Aglen HE, Gundersen SG, Bruun JN (2008) Predictors of mortality in HIV-infected patients starting antiretroviral therapy in a rural hospital in Tanzania. BMC Infect Dis 8:52

Kaboski JP, Townsend RM (2008) A structural evaluation of a large-scale quasi-experimental microfinance initiative. In: MIT Department of Economics Working Paper No. Mass Institute of Technology, Boston, pp 09-12

Kalichman SC, Simbayi LC, Cloete A, Mthembu PP, Mkhonta RN, Ginindza T (2009) Measuring AIDS stigmas in people living with HIV/AIDS: the Internalized AIDS-Related Stigma Scale. AIDS Care 21(1):87-93

Kalichman SC, Cherry C, Amaral C, White D, Kalichman MO, Pope H, Swetsze C, Jones M, Macy R (2010a) Health and treatment implications of food insufficiency among people living with HIV/AIDS, Atlanta. Georgia J Urban Health 87(4):631-641

Kalichman SC, Cherry C, Amaral CM, Swetzes C, Eaton L, Macy R, Grebler T, Kalichman MO (2010b) Adherence to antiretroviral therapy and HIV transmission risks: implications for test-and-treat approaches to HIV prevention. AIDS Patient Care STDS 24(5):271-277

Kenya National Bureau of Statistics and ICF Macro (2010) Kenya Demographic and Health Survey 2008-09. Kenya National Bureau of Statistics and ICF Macro, Calverton, Maryland

Kihia JK, Kamau RN (1999) Super-Money Maker pressure pedal pump impact assessment in utilisation, job creation and income generation. In. ApproTEC, Inc., Nairobi

Kim J, Pronyk P, Barnett T, Watts C (2008) Exploring the role of economic empowerment in HIV prevention. Aids 22:S57-S71

Kotler DP, Tierney AR, Brenner SK, Couture S, Wang J, Pierson RN Jr (1990) Preservation of short-term energy balance in clinically stable patients with AIDS. Am J Clin Nutr 51(1):7-13

Larson B, Fox M, Rosen S, Bii M, Sigei C, Shaffer D, Sawe F, Wasunna M, Simon J (2008) Early effects of antiretroviral therapy on work performance: preliminary results from a cohort study of Kenyan agricultural workers. AIDS 22(3):421

Lee JS, Frongillo EA Jr (2001) Nutritional and health consequences are associated with food insecurity among U.S. elderly persons. J Nutr 131(5):1503-1509

Lewis Kulzer J, Penner JA, Marima R, Oyaro P, Oyanga AO, Shade SB, Blat CC, Nyabiage L, Mwachari CW, Muttai HC, Bukusi EA, Cohen CR (2012) Family model of HIV care and treatment: a retrospective study in Kenya. J Int AIDS Soc 15(1):8

Liegeois F, Vella C, Eymard-Duvernay S, Sica J, Makosso L, Mouinga-Ondeme A, Mongo AD, Boue V, Butel C, Peeters M, Gonzalez JP, Delaporte E, Rouet F (2012) Virological failure rates and HIV-1 drug resistance patterns in patients on first-line antiretroviral treatment in semirural and rural Gabon. J Int AIDS Soc 15(2):17985

Macallan DC, Noble C, Baldwin C, Jebb SA, Prentice AM, Coward WA, Sawyer MB, McManus TJ, Griffin GE (1995) Energy expenditure and wasting in human immunodeficiency virus infection. N Engl J Med 333(2):83-88

Mahlungulu S, Grobler LA, Visser ME, Volmink J (2007) Nutritional interventions for reducing morbidity and mortality in people with HIV. Cochrane Database Syst Rev 3, CD004536

Mamlin J, Kimaiyo S, Lewis S, Tadayo H, Jerop FK, Gichunge C, Petersen T, Yih Y, Braitstein P, Einterz R (2009) Integrating nutrition support for food-insecure patients and their dependents into an HIV care and treatment program in Western Kenya. Am J Public Health 99(2):215-221

Mast TC, Kigozi G, Wabwire-Mangen F, Black R, Sewankambo N, Serwadda D, Gray R, Wawer M, Wu AW (2004) Measuring quality of life among HIV-infected women using a culturally adapted questionnaire in Rakai district Uganda. AIDS Care 16(1):81-94

Mbugua S, Andersen N, Tuitoek P, Yeudall F, Sellen D, Karanja N, Cole D, Njenga $M$, Prain G (2008) Assessment of food security and nutrition status among households affected by HIV/AIDS in Nakuru Municipality, Kenya. XVII International AIDS Conference, Mexico City

Mclntyre D, Thiede M, Dahlgren G, Whitehead M (2006) What are the economic consequences for households of illness and of paying for health care in low-and middle-income country contexts? Soc Sci Med 62(4):858-865

McMahon JH, Wanke CA, Elliott JH, Skinner S, Tang AM (2011) Repeated assessments of food security predict CD4 change in the setting of antiretroviral therapy. J Acquir Immune Defic Syndr 58(1):60-63

Miller CL, Bangsberg DR, Tuller DM, Senkungu J, Kawuma A, Frongillo EA, Weiser SD (2011) Food insecurity and sexual risk in an HIV endemic community in Uganda. AIDS Behav 15(7):1512-1519
Nagata JM, Magerenge RO, Young SL, Oguta JO, Weiser SD, Cohen CR (2012) Social determinants, lived experiences, and consequences of household food insecurity among persons living with HIV/AIDS on the shore of Lake Victoria, Kenya. AIDS Care 24(6):728-736

Njenga M, Karanja N, Gathuru K, Mbugua S, Fedha N, Ngoda B (2009) The role of women-led micro-farming activities in combating HIV/AIDS in Nakuru, Kenya. In: Hovorka A, de Zeeuw H, Njenga M (eds) Women feeding cities: mainstreaming gender in urban agriculture and food security. Practical Action Publishing, Warwickshire, Rugby, UK

Normen L, Chan K, Braitstein P, Anema A, Bondy G, Montaner JS, Hogg RS (2005) Food insecurity and hunger are prevalent among HIV-positive individuals in British Columbia. Canada J Nutr 135(4):820-825

Nutrition and HIV/AIDS (2001) Statement by the Administrative Committee on Coordination, Sub-Committee on Nutrition at its 28th Session. United Nations Administrative Committee on Coordination, Sub-Committee on Nutrition, Nairobi, Kenya

Oakley A, Strange V, Bonell C, Allen E, Stephenson J (2006) Process evaluation in randomised controlled trials of complex interventions. British Medical Journal 332(7538):413-416

Ochai R (2008) HIV, livelihoods, nutrition and health research. Global Ministerial Forum on Research for Health: 2008, Bamako, Mali

Oyugi J, Byakika-Tusiime J, Charlebois E, Kityo C, Mugerwa R, Mugyenyi P, Bangsberg D (2004) Multiple validated measures of adherence indicate high levels of adherence to generic HIV antiretroviral therapy in a resource-limited setting. J Acquir Immune Defic Syndr 36(5):1100-1102

Oyugi JH, Byakika-Tusiime J, Ragland K, Laeyendecker O, Mugerwa R, Kityo C, Mugyenyi P, Quinn TC, Bangsberg DR (2007) Treatment interruptions predict resistance in HIV-positive individuals purchasing fixed-dose combination antiretroviral therapy in Kampala. Uganda Aids 21(8):965-971

Pandit JA, Sirotin N, Tittle R, Onjolo E, Bukusi EA, Cohen CR (2010) Shamba Maisha: a pilot study assessing impacts of a micro-irrigation intervention on the health and economic wellbeing of HIV patients. BMC Pub Health 10:245

Parienti JJ, Massari V, Descamps D, Vabret A, Bouvet E, Larouze B, Verdon R (2004) Predictors of virologic failure and resistance in HIV-infected patients treated with nevirapine- or efavirenz-based antiretroviral therapy. Clin Infect Dis 38(9):1311-1316

Parienti JJ, Das-Douglas M, Massari V, Guzman D, Deeks SG, Verdon R, Bangsberg DR (2008) Not all missed doses are the same: sustained NNRTI treatment interruptions predict HIV rebound at low-to-moderate adherence levels. PLoS ONE 3(7):e2783

Petersen ML, Sinisi SE, van der Laan MJ (2006) Estimation of direct causal effects. Epidemiology 17(3):276-284

Physical Status (1995) The Use and Interpretation of Anthropometry. Report of a WHO Expert Committee. WHO Technical Report Series 854. In. World Health Organization, Geneva, Switzerland

Pronyk PM, Hargreaves JR, Kim JC, Morison LA, Phetla G, Watts C, Busza J, Porter JD (2006) Effect of a structural intervention for the prevention of intimate-partner violence and HIV in rural South Africa: a cluster randomised trial. Lancet 368(9551):1973-1983

Pulerwitz J, Gortmaker SL, DeJong W (2000) Measuring sexual relationship power in HIV/STD research. Sex Roles 42(7-8):637-660

Robinson J, Yeh E (2011) Transactional sex as a response to risk in western Kenya. Am Econ J Appl Econ 3:35-64

Rose D, Oliveira V (1997) Nutrient intakes of individuals from food-insufficient households in the United States. Am J Public Health 87(12):1956-1961

Russell S (2004) The economic burden of illness for households in developing countries: a review of studies focusing on malaria, tuberculosis, and human immunodeficiency virus/acquired immunodeficiency syndrome. Am J Trop Med Hygiene 71(2 Suppl):147-155

Schuler SR, Hashemi SM (1994) Credit Programs, Womens Empowerment, And Contraceptive Use In Rural Bangladesh. Stud Family Plan 25(2):65-76

Siedner MJ, Tsai AC, Dworkin S, Mukiibi NF, Emenyonu NI, Hunt PW, Haberer JE, Martin JN, Bangsberg DR, Weiser SD (2012) Sexual relationship power and malnutrition among HIV-positive women in rural Uganda. AIDS Behav 16(6):1542-1548

Stack JA, Bell SJ, Burke PA, Forse RA (1996) High-energy, high-protein, oral, liquid, nutrition supplementation in patients with HIV infection: effect on weight status in relation to incidence of secondary infection. J Am Diet Assoc 96(4):337-341 
Stevens JE (2002) Martin makes a middle class: Stanford grad Martin Fisher has gone low-tech in search of solutions for Kenyan farmers. SF Chronicle Magazine, San Francisco, p 18

Stewart R, Rooyen C, Dickson K, Majoro M, Wet T (2010) What is the impact of microfinance on poor people?: a systematic review of evidence from sub-Saharan Africa. In. EPPI-Centre, Social Science Research Unit, Institute of Education, University of London, London

Stringer JS, Zulu I, Levy J, Stringer EM, Mwango A, Chi BH, Mtonga V, Reid S, Cantrell RA, Bulterys M, Saag MS, Marlink RG, Mwinga A, Ellerbrock TV, Sinkala M (2006) Rapid scale-up of antiretroviral therapy at primary care sites in Zambia: feasibility and early outcomes. JAMA 296(7):782-793

Swindale A, Bilinsky P (2006) Development of a universally applicable household food insecurity measurement tool: process, current status, and outstanding issues. J Nutr 136(5):1449S-1452S

Sztam KA, Fawzi WW, Duggan C (2010) Macronutrient supplementation and food prices in HIV treatment. J Nutr 140(1):213S-223S

Tsai AC, Bangsberg DR, Emenyonu N, Senkungu JK, Martin JN, Weiser SD (2011) The social context of food insecurity among persons living with HIV/AIDS in rural Uganda. Soc Sci Med 73(12):1717-1724

Tsai AC, Bangsberg DR, Frongillo EA, Hunt PW, Martin JN, Weiser SD (2012) Food insecurity, depression and the modifying role of social support among people living with HIV/AIDS in Rural Uganda. Soc Sci Med 74(12):2012-2019

Tsai AC, Bangsberg DR, Kegeles SM, Katz IT, Muzoora C, Martin JN, Weiser SD (2013) Internalized stigma, disease progression, and serostatus disclosure among people living with HIV/AIDS in rural Uganda. Ann Behav Med 46(3):285-294

Tucker JS, Burnam MA, Sherbourne CD, Kung FY, Gifford AL (2003) Substance use and mental health correlates of nonadherence to antiretroviral medications in a sample of patients with human immunodeficiency virus infection. Am J Med 114(7):573-580

Tuller DM, Bangsberg DR, Senkungu J, Ware NC, Emenyonu N, Weiser SD (2010) Transportation costs impede sustained adherence and access to HAART in a clinic population in southwestern Uganda: a qualitative study. AIDS Behav 14(4):778-784

UNAIDS Policy Brief (2008) HIV/AIDS, HIV, Food Security and Nutrition.

Wang EA, McGinnis KA, Fiellin DA, Goulet $J$, Bryant K, Gibert CL, Leaf DA, Mattocks K, Sullivan LE, Vogenthaler N, Sullivan LE, Vogenthaler N, Justice AC (2011) Food insecurity is associated with poor virologic response among HIV-infected patients receiving antiretroviral medications. J Gen Intern Med 26(9):1012-1018

Webb-Girard A, Cherobon A, Mbugua S, Kamau-Mbuthia E, Amin A, Sellen DW (2012) Food insecurity is associated with attitudes towards exclusive breastfeeding among women in urban Kenya. Matern Child Nutr 8(2):199-214

Weinhardt LS, Galvao LW, Stevens PE, Masanjala WH, Bryant C, Ng'ombe T (2009) Broadening research on microfinance and related strategies for HIV prevention: commentary on Dworkin and Blankenship (2009). AIDS Behav 13(3):470-473

Weiser SD, Wolfe WR, Bangsberg DR (2004) The HIV epidemic among individuals with mental illness in the United States. Curr HIV/AIDS Rep 1(4):186-192

Weiser SD, Leiter K, Bangsberg DR, Butler LM, Percy-de Korte F, Hlanze Z, Phaladze N, lacopino V, Heisler M (2007) Food insufficiency is associated with high-risk sexual behavior among women in Botswana and Swaziland. PLoS Med 4(10):1589-1597, discussion 1598

Weiser SD, Frongillo EA, Ragland K, Hogg RS, Riley ED, Bangsberg DR (2009a) Food insecurity is associated with incomplete HIV RNA suppression among homeless and marginally housed HIV-infected individuals in San Francisco. J Gen Intern Med 24(1):14-20

Weiser SD, Fernandes KA, Brandson EK, Lima VD, Anema A, Bangsberg DR, Montaner JS, Hogg RS (2009b) The association between food insecurity and mortality among HIV-infected individuals on HAART. J Acq Immune Def Syndromes 52(3):342-349

Weiser SD, Bangsberg DR, Kegeles S, Ragland K, Kushel MB, Frongillo EA (2009c) Food insecurity among homeless and marginally housed individuals living with HIV/AIDS in San Francisco. AIDS Behav 13(5):841-848

Weiser S, Fernandes K, Anema A, Brandson E, Lima V, Montaner J, Hogg R (2009d) Food insecurity as a barrier to antiretroviral therapy (ART) adherence among HIV-infected individuals in British Columbia (2009d). 5th IAS Conference on HIV Pathogenesis, Treatment and Prevention, Cape Town, South Africa

Weiser SD, Tsai AC, Senkungu J, Emenyonu N, Kawuma A, Hunt P, Martin J, Bangsberg DR (2010a) The impact of low sexual relationship power on viral load suppression among women receiving antiretroviral therapy in Mbarara,
Uganda. 17th Conference on Retroviruses and Opportunistic Infections, San Francisco

Weiser SD, Tuller DM, Frongillo EA, Senkungu J, Mukiibi N, Bangsberg DR (2010b) Food insecurity as a barrier to sustained antiretroviral therapy adherence in Uganda. PLoS One 5(4):e10340

Weiser SD, Young SL, Cohen CR, Kushel MB, Tsai AC, Tien PC, Hatcher AM, Frongillo EA, Bangsberg DR (2011) Conceptual framework for understanding the bidirectional links between food insecurity and HIV/AIDS. Am J Clin Nutr 94(6):1729S-1739S

Weiser SD, Tsai AC, Gupta R, Frongillo EA, Kawuma A, Senkungu J, Hunt PW Emenyonu NI, Mattson JE, Martin JN, Bangsberg DR (2012) Food insecurity is associated with morbidity and patterns of healthcare utilization among HIV-infected individuals in a resource-poor setting. AIDS 26(1):67-75

Wolfe WR, Weiser SD, Leiter K, Steward WT, Percy-de Korte F, Phaladze N, lacopino V, Heisler M (2008) The impact of universal access to antiretroviral therapy on HIV stigma in Botswana. Am J Public Health 98(10):1865-1871

World Bank (2010) Yes, Africa can: success stories from a dynamic continent. The World Bank, Washington, D.C

World Food Program (2003) Programming in the Era of AIDS: WFP's Response to HIV/AIDS, WFP/EB.1/2003/4-B.

Wu AW, Rubin HR, Mathews WC, Ware JE Jr, Brysk LT, Hardy WD, Bozzette SA, Spector SA, Richman DD (1991) A health status questionnaire using 30 items from the Medical Outcomes Study Preliminary validation in persons with early HIV infection. Med Care 29(8):786-798

Zachariah R, Fitzgerald M, Massaquoi M, Pasulani O, Arnould L, Makombe S, Harries AD (2006) Risk factors for high early mortality in patients on antiretroviral treatment in a rural district of Malawi. Aids 20(18):2355-2360

\section{Submit your manuscript to a SpringerOpen ${ }^{\circ}$ journal and benefit from:}

- Convenient online submission

- Rigorous peer review

- Immediate publication on acceptance

- Open access: articles freely available online

- High visibility within the field

- Retaining the copyright to your article

Submit your next manuscript at $>$ springeropen.com 